\title{
Responsabilidade civil dos profissionais de enfermagem nos procedimentos invasivos
}

\author{
Damage liability of nursing professionals in the invasive procedures
}

Responsabilidad civil de los profesionales de enfermería en procedimientos invasivos

\section{Cristina Maria Miranda de Sousa', Maria Eliete Batista Moura', Ana Maria Ribeiro dos Santos', Benevina Maria Vilar Teixeira Nunes', Maria do Socorro Costa Feitosa Alves" \\ 'Faculdade NOVAFAPI. Grupo de Estudos e Pesquisa sobre Representações Sociais. Teresina, PI \\ "Universidade Federal do Rio Grande do Norte. Natal, RN}

Submissão: 04/05/2009

Aprovação: 3 1/08/2009

\section{RESUMO}

Este estudo teve por objetivo apreender as Representações Sociais da Responsabilidade Civil da Enfermagem nos procedimentos invasivos elaboradas pelos profissionais da área. Trata-se de uma pesquisa Qualitaitva desenvolvida em um hospital público com 64 sujeitos. Os dados foram produzidos a partir do Teste de Associação Livre de Palavras, processados pelo software Tri-Deux Mots, sendo feita Análise Fatorial de Correspondência. O campo representacional dos sujeitos indicou atitudes favoráveis com relação ao estímulo procedimentos invasivos. As concepções sobre o estímulo infecção hospitalar demonstraram uma visão ampla do problema das infecções hospitalares e suas graves conseQuências. Porém, não se observou preocupação e manifestação nas representações sociais dos sujeitos sobre as responsabilidades civil do profissional de Enfermagem.

Descritores: Responsabilidade civil; Psicologia social; Infecção hospitalar.

\section{ABSTRACT}

This study had as objective to apprehend the Social Representation of damage liability of nursing in the invasive procedures elaborated by the professionals of the area. It treats of a Qualitaitve research, developed in a public hospital with 64 fellows. The data were produced from the free association words test, processed by software Tri-Deux Mots, being done Correspondence Factorial Analysis. The fellow's representational field indicated favorable attitudes in relation to the invasive procedures stimulus. The conceptions about hospital infection stimulus demonstrated a broad vision of hospital infection problem and its serious consequences. However it was not observed preoccupation and manifestation in the fellow's social representations about the civil responsibilities of Nursing professional.

Descriptors: Damage liability; Psychology, social; Cross infection.

\section{RESUMEN}

Este estudio tuvo como objetivo aprehender las Representaciones Sociales de la Responsabilidad Civil de Enfermería en los procedimientos invasivos elaborados por los profesionales del área. Tratase de una investigación cualitativa desarrollada en un hospital estatal con 64 sujetos. Los datos fueron producidos a partir de examen de asociación libre de palabras, procesadas por el software Tri-Deux Mots, siendo hecho Análisis Factorial de Correspondencia. El campo representacional de los sujetos indicó actitudes favorables con relación al estímulo procedimientos invasivos. Las concepciones sobre el estímulo infección hospitalario demostraron una visión amplia del problema de las infecciones hospitalarios y sus graves consecuencias. Sin embargo no se observó preocupación y manifestación en las representaciones sociales del sometido sobre las responsabilidades civil del profesional de Enfermería.

Descriptores: Responsabilidad civil; Psicología social; Infección hospitalaria. 


\section{INTRODUÇÃO}

A problemática da infecção hospitalar por ser tão antiga Quanto a prática do agrupamento de pessoas doentes, com a finalidade de receber tratamento numa hospitalização, tornou-se uma temática de interesse por diferentes áreas do conhecimento, caracterizandose como um fenômeno interdisciplinar. O hospital, nessa concepção, tem propiciado condições para a transmissão de infecção ao favorecer a relação paciente, agente infectante e ambiente hospitalar. Contudo, cabe registrar Que a infecção hospitalar ou nosocomial é aQuela definida como uma infecção adQuirida após a internação do paciente e Que se manifesta durante o período de internação ou mesmo após a alta, até 30 dias, Quando puder ser relacionada com a hospitalização $\mathrm{O}^{(1)}$.

No Brasil, esta problemática é considerada grave tendo em vista Que 720.000 pessoas são infectadas em hospitais brasileiros por ano e, dessas, 144.000, ou seja, 20\%, evoluem para a morte. Esta situação é agravada pelo índice de tolerância das infecções hospitalares, Que em nosso país encontra-se em torno de 6\%, triplicando o percentual de tolerância da Organização Mundial de Saúde (OMS), fato este Que agrava a situação dos hospitais brasileiros, pois o custo do paciente com infecção hospitalar é três vezes maior do Que o custo do paciente sem infecção hospitalar ${ }^{(2)}$.

Neste contexto, salientam-se os procedimentos invasivos realizados na grande maioria dos pacientes internados Que, por abrirem vias de acesso aos tecidos estéreis do organismo, tornamse causa de infecção hospitalar, dependendo dos cuidados de assepsia e anti-sepsia tomados para o procedimento e do estado geral do paciente ${ }^{(3)}$. Neste estudo, considera-se procedimento invasivo aquele Que rompe as barreiras naturais do organismo ou penetra em suas cavidades ${ }^{(4)}$.

A esse respeito, é evidente Que a infecção hospitalar tem crescido proporcionalmente ao desenvolvimento da tecnologia invasiva, no entanto, parece que o conhecimento dos profissionais da saúde sobre as ações de prevenção e controle das infecções não acompanha esse desenvolvimento.

O uso inadequado e generalizado dos procedimentos invasivos, diagnósticos e terapêuticos, juntamente com os problemas do índice de tolerância têm agravado a situação das infecções hospitalares. Daí a necessidade de prevenção e tratamento das infecções precocemente, possibilitando alternativas de conhecimento da problemática e das medidas de prevenção e controle pelos profissionais da saúde.

Dessa forma, os profissionais de Enfermagem Que lidam com procedimentos invasivos devem estar conscientes da possibilidade, atribuída a eles enquanto sujeitos da ação invasiva, da responsabilidade civil pelos possíveis danos desta ação. Diniz, vale ressaltar, conceitua responsabilidade civil como "aplicação de medidas Que obriguem uma pessoa a reparar dano moral ou patrimonial causado a terceiros, em razão de ato por ela mesma praticado, por pessoa por Quem ela responde, por alguma coisa a ela pertencente ou de simples imposição legal"(5).

A responsabilidade civil do Enfermeiro está regulamentada tanto no Código Civil Quanto na Legislação específica da profissão. No Código Civil, artigo 186, tal conceito está disposto como "auuele Que, por ação ou omissão voluntária, negligência ou imprudência, violar direito e causar dano a outrem, ainda Que exclusivamente moral, comete ato ilícito”(6). Sendo Que o artigo 927 estabelece Que "aquele que, por ato ilícito (arts. 186 e 187), causar dano a outrem, fica obrigado a repará-lo”(6).

Nas Normas específicas da profissão, como é o caso da Resolução COFEN 240/2000, Que aprova o Código de Ética dos Profissionais da Enfermagem e contêm os princípios fundamentais, direitos, deveres, proibições, infrações e penalidades Que cabem aos profissionais da Enfermagem no exercício de sua profissão, destacam-se as seguintes responsabilidades:

"Art. 16 Assegurar ao cliente uma assistência de Enfermagem livre de danos decorrentes de imperícia, negligência ou imprudência".

"Art. 18 Manter-se atualizado, ampliando seus conhecimentos técnicos, científicos e culturais, em beneficio de clientela, coletividade e do desenvolvimento da profissão".

"Art. 20 Responsabilizar-se por falta cometida em suas atividades profissionais, independente de ter sido praticada individualmente ou em equipe"(7).

A adoção dos princípios contidos no instrumento Que normatiza a profissão do Enfermeiro deveria, pois, orientar Qual Quer ação deste profissional como alternativa para a prevenção de ocorrências Que implieuem na responsabilidade civil.

Pela relevância dessa problemática, optou-se por se realizar este estudo, subsidiado na Teoria das Representações Sociais, pelo seu caráter interdisciplinar e pela opção de diferentes pesQuisadores, Que nos últimos anos têm visto nesta teoria um caminho favorável para se conhecer dimensões subjetivas ligadas à saúde. Os pesquisadores têm-se interessado por essa abordagem pela possibilidade de estudar a produção simbólica como uma forma de realizar pesquisas mais criativas, pela valorização do saber popular e pela possibilidade de revelar situações do cotidiano da prática não visíveis objetivamente ${ }^{(8)}$.

O conceito de Representação Social foi originado na Europa com a publicação feita por Serge Moscovici, do seu estudo sobre a Representação Social da psicanálise. Para esse autor as Representações Sociais são: um sistema de valores, idéias e práticas, com uma dupla função: primeiro, estabelecer uma ordem Que possibilitará às pessoas orientar-se em seu mundo material e social e controla-lo; e, segundo lugar, possibilitar Que a comunicação seja possível entre os membros de uma comunidade, fornecendolhe um código para nomear e classificar, sem ambiguidade, os vários aspectos de seu mundo e da sua história individual e social ${ }^{(9)}$.

A Representação Social compreende "uma forma de conhecimento, socialmente elaborada e partilhada, Que tem um objetivo prático e concorrendo para a construção de uma realidade comum a um conjunto social"(10).

Assim, definiu-se como objeto de estudo as Representações Sociais da Responsabilidade Civil dos Profissionais de Enfermagem nos Procedimentos Invasivos e, como objetivo, apreender os fenômenos sócio-culturais dessas Representações.

\section{METODOLOGIA}

Trata-se de um estudo de abordagem Qualitativa, fundamentado na Teoria das Representações Sociais, por sua adeQuação ao estudo da problemática apresentada, e por melhor apreender os fenômenos sócio-culturais das Representações Sociais relacionadas com os 
Procedimentos Invasivos.

O cenário da pesquisa foi um hospital público de grande porte, localizado em Teresina, sendo referência para todo o Estado do Piauí e estados vizinhos. A pesquisa teve como sujeitos, 64 profissionais de Enfermagem, sendo 30 de nível superior e 34 de nível médio, Que desenvolvem atividades nessa instituição, observando as Diretrizes e Normas Regulamentadoras de Pesquisas envolvendo Seres Humanos, de acordo com a Resolução 196/1996.

Uma vez organizados os dicionários e o banco de dados, estes foram produzidos a partir do Teste de Associação Livre de Palavras (TALP), Que se estrutura sobre a evocação das respostas dadas aos estímulos indutores e processados pelo software Tri-Deux Mots Que deram origem a um conjunto de 417 palavras originadas dos estímulos infecção hospitalar e procedimentos invasivos. Destas, 133 com significados diferentes. Para análise do material final deste processo, foram consideradas as modalidades Que obtiveram a contribuição por fator superior a duas vezes a média, Que corresponde às modalidades ou palavras Que contribuíram com maior significação na construção dos fatores ${ }^{(1)}$, interpretados por meio da Análise Fatorial de Correspondência (AFC).

O gráfico Que foi construído a partir desse processo corresponde aos adjetivos Que os sujeitos evocaram a respeito do objeto em estudo, isto é, ao mapa dos agrupamentos e oposições entre os adjetivos associados aos procedimentos invasivos e infecção hospitalar. Apresenta, portanto, resultados Que permitiram uma avaliação estatística dos dados no Que concerne à frequência (importância da contribuição das modalidades na construção dos fatores) e a representação gráfica das variações semânticas na definição do campo espacial.

\section{RESULTADOS E DISCUSSÃO}

\section{As Representações Sociais dos Procedimentos Invasivos}

As concepções e percepções dos sujeitos sobre procedimentos invasivos possibilitaram, pela ótica das Representações Sociais, edificar conceitos, explicações e afirmações Que se originam no cotidiano através das comunicações interindividuais e do conhecimento socialmente elaborado e compartilhado. O conhecimento vincula-se às construções sociais influenciadas pela cultura (opiniões, atitudes e estereótipos), pelos grupos sociais e pela história. Portanto, as Representações Sociais contribuem para a formação de condutas e orientação das comunicações, podendo ser entendida como uma teoria do "senso comum", designando uma forma de pensamento social ${ }^{(10)}$.

No gráfico 1, a seguir, observa-se o conteúdo das representações sobre procedimentos invasivos, tornando-se possível, a partir da objetivação configurada no campo representacional, fazer a leitura e interpretação das modalidades de opinião pelas palavras evocadas, correlacionando-as com as variáveis fixas organizadas segundo os eixos ou fatores (FI e F2). Apresentam-se em itálico as modalidades Que compõem o fator $\mathrm{Fl}$; em negrito, as modalidades do fator F2 e, sublinhada, as modalidades comuns aos dois fatores, destacandose com um asterisco a variável fixa.

\section{Fator 1 - lado esQuerdo (negativo)}

Destacam-se no gráfico, do lado esQuerdo negativo do fator 1 , as representações sociais da infecção hospitalar e dos procedimentos invasivos, elaboradas por profissionais de Enfermagem de nível superior, de 20 a 30 anos de idade.

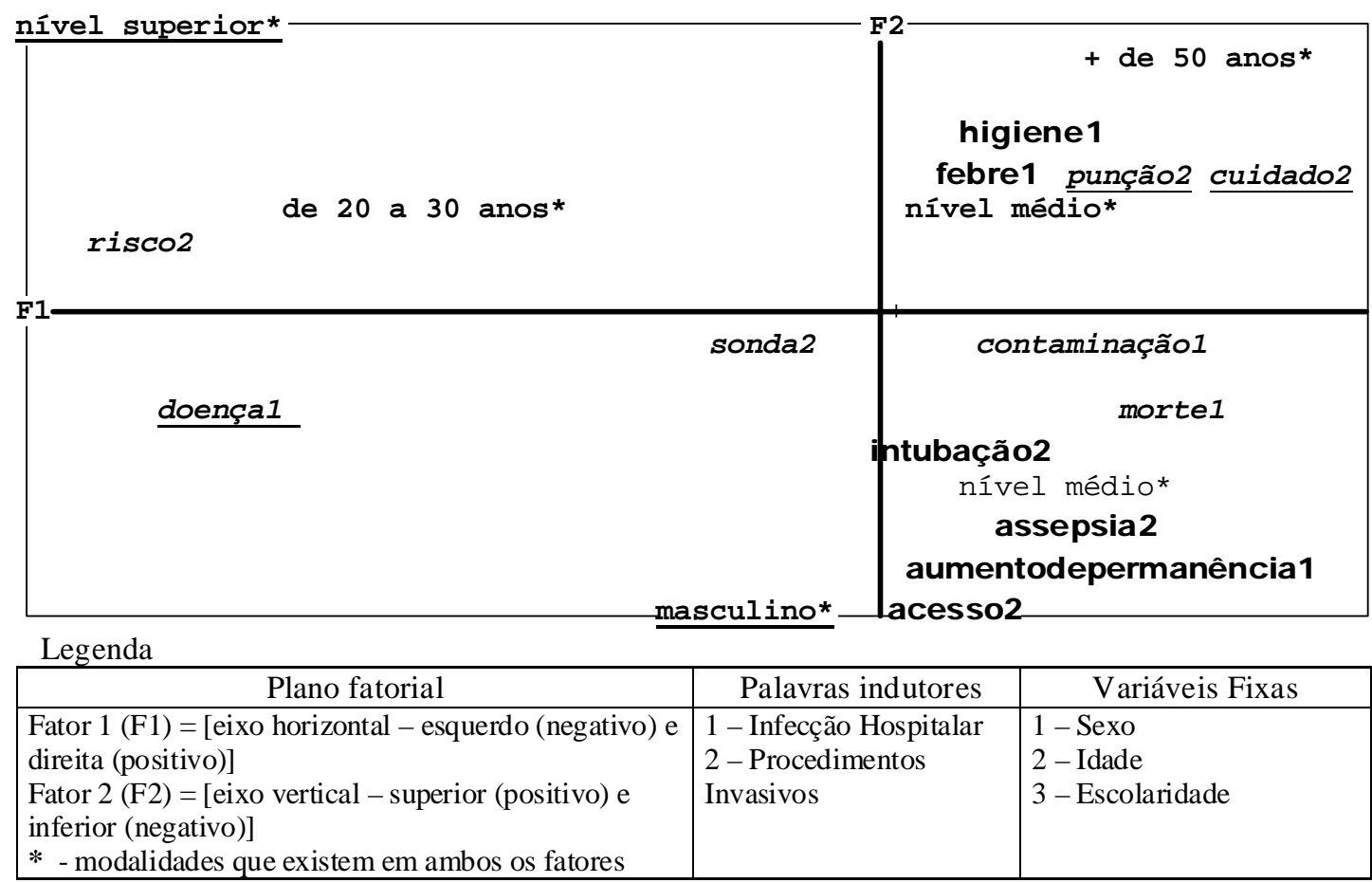

Gráfico 1. Representação gráfica do plano fatorial sobre os Procedimentos Invasivos. 
Segundo esse grupo de sujeitos, infecção hospitalar tem sentido de doença. Através dessas modalidades os profissionais reconhecem a infecção hospitalar como uma doença, todavia, no campo representacional, não se referem às medidas de prevenção e controle das infecções como um aspecto inerente à doença. Questiona-se, então, por Que esses profissionais não aderem às práticas preventivas comprovadamente eficientes.

Vários fatos indicam a necessidade de um investimento anterior à prática, isto é, ainda na formação profissional, pois a mudança de comportamento é processo, uma vez Que vários fatores interferem na aceitação de normas técnicas de prevenção e de seguridade ${ }^{(12)}$.

A representação dos procedimentos invasivos é descrita pelos profissionais de Enfermagem de nível superior como: risco e sonda. Essas representações apresentam-se vinculadas aos procedimentos de risco, sendo um deles enumerado como sonda, um sério fator de risco exógeno, além de outros fatores endógenos Que predispõem a infecção.

Pesquisa aponta Que após análise dos prontuários de 188 pacientes sondados com urocultura positiva, depois de decorrido um período de pelo menos $48 \mathrm{hs}$ da internação, verificou-se Que os microorganismos mais comuns foram E. coli (26\%), Klebsiella sp (15\%), P. aeruginosa (15\%) e Enterococcus sp (11\%). O estudo permitiu concluir Que a infecção urinária é a mais comum das infecções hospitalares e Que o conhecimento das cepas bacterianas e do antibiograma é importante para orientar no tratamento ${ }^{(13)}$.

No entanto, sabe-se também Que o risco de infecção durante a realização de um procedimento invasivo está relacionado à utilização correta da técnica, sem contaminação dos materiais e equipamentos, além da eficácia dos anti-sépticos empregados. Portanto, verificase Que a educação permanente aliada à pesQuisa científica são aspectos fundamentais na formação de uma equipe multiprofissional crítica e consciente de sua responsabilidade no controle e prevenção das infecções associadas a esse tipo de procedimento. Nesse sentido, vale ressaltar os fatores considerados de riscos relativos ao trato urinário: tempo de utilização do dispositivo, o material e tipo de sistema de drenagem utilizado, manutenção da permeabilidade do sistema, manipulação com tração adęuada e controle de posicionamento do cateter, o anti-séptico utilizado na inserção, além da lavagem adeQuada das mãos dos profissionais antes e após o manuseio do cateter ${ }^{(4)}$.

\section{Fator 1- lado direito (positivo)}

No lado oposto, direito positivo, do mesmo fator (FI), observase a delimitação do agrupamento das Representações Sociais sobre os mesmos estímulos infecção hospitalar e procedimentos invasivos, construídas por profissionais do nível médio.

Neste lado do eixo, infecção hospitalar tem sentido de contaminação e morte. Através dessa modalidade, os profissionais de Enfermagem de nível médio, reconhecem Que a infecção hospitalar é favorecida pelo descuido dos pacientes com relação à sua higiene pessoal bem como pela limpeza inadequada do ambiente hospitalar em Que estes se encontram, levando ao aumento do tempo de permanência hospitalar. Tais elementos contribuem para infecção hospitalar, causando a contaminação de uma forma geral e com a possibilidade da evolução para morte.

Alguns autores acreditam Que os critérios de Qualidade da limpeza são subjetivos. Inicialmente, a limpeza é avaliada visualmente através da presença de resíduos sólidos no chão ou manchas de líquidos secos. Além disso, muitas vezes uma limpeza terminal é substituída por uma limpeza simples devido à falta de material e equipamento, prejudicando assim a Qualidade do trabalho dos profissionais responsáveis pela higienização do hospital ${ }^{(14)}$.

Os procedimentos invasivos são expressos pelos profissionais, nesse fator, como punção e cuidado. Dessa forma, os procedimentos punção e cuidado foram representados como aqueles Que requerem medidas assépticas. Quanto maior a manipulação de objetos perfurocortantes e de sangue ou outros fluídos orgânicos, maior a exposição e maior o risco para doenças como AIDS e as hepatites $\mathrm{B}$ e $\mathrm{C}^{(4)}$.

A terapia endovenosa e a punção para coleta de sangue são os procedimentos mais comuns realizados no mundo, relacionados ao sistema vascular, Que, por permitirem acesso direto à corrente sanguínea, podem conduzir à sepse ou causar disseminação hematogênica a outros sítios do organismo.

Assim sendo, todos requerem cuidado e medidas assépticas rigorosas durante seu desenvolvimento. O cuidado pode ser avaliado, pelos sujeitos, como fator essencial para a prevenção, minimização ou eliminação de riscos inerentes às atividades de pesquisa, produção, ensino, desenvolvimento tecnológico e prestação de serviços ${ }^{(15)}$.

\section{Fator 2 - lado inferior (negativo)}

No fator 2, no lado inferior negativo do gráfico, destacam-se as Representações sobre infecção hospitalar e procedimentos invasivos elaboradas por profissionais de Enfermagem de nível médio do sexo masculino.

As modalidades correspondentes às variáveis de opinião evocadas por esses profissionais em resposta ao estímulo infecção hospitalar são representadas pelas palavras: doença e aumento de permanência. Desse modo, configuram-se evocações cujo foco foi centralizado na infecção como doença Que leva a um aumento de permanência hospitalar da clientela. Nesse sentido, é importante lembrar Que a formação é o momento propício para o ensino do controle de infecção a fim de construir um padrão de conduta alicerçado na fundamentação técnica consistente, na formação de hábitos e atitudes Que possam subsidiar práticas profissionais futuras mais seguras e competentes.

Dentre as infecções hospitalares, as infecções de sítio cirúrgico constituem um grave problema, sendo estas responsáveis, em muitos casos, pelo retorno do paciente ao hospital, considerando Que devido ao curto período de internação a maioria das infecções se manifesta após a alta hospitalar, ou o aumento da permanência, Quando a infecção é diagnosticada durante a internação.

Pesquisa comprovou, em um estudo epidemiológico comparativo do diagnóstico da infecção do sítio cirúrgico, durante e após a internação, a importância do segmento pós-alta para a obtenção de dados fidedignos sobre essas infecções, Quando o paciente tem um curto período de internação, ressaltando Que a vigilância específica do paciente após a alta hospitalar é considerada fundamental para controlar as infecções ${ }^{(16)}$.

Em relação aos procedimentos invasivos, destacam-se as palavras: intubação, assepsia e acesso. As palavras evocadas revelam Que estes procedimentos podem favorecer às infecções hospitalares. Os profissionais demonstraram conhecer 
procedimentos invasivos Que contribuem para a proliferação dessas infecções.

A falta dos mecanismos de defesa do trato respiratório superior, com consequente entrada de ar direto na traquéia, sem anteriormente ser aQuecido e umidificado pelo organismo, são as ocorrências mais comuns à intubação endotraQueal. Além disso, o risco de trauma traqueobrônquico, resultante do procedimento de aspiração de grande Quantidade de secreção Que poderá secar rapidamente e obstruir o tubo, tem contribuído para que a colonização do trato respiratório por bacilos Gram-negativos ocorra em todos os pacientes a partir do terceiro dia de intubação ${ }^{(4)}$.

\section{Fator 2 - lado superior (positivo)}

No fator 2, no lado superior positivo do gráfico I, encontramse as objetivações de infecção hospitalar e procedimentos invasivos, construídas por profissionais de Enfermagem de nível superior e médio com mais de 50 anos.

Em resposta a infecção hospitalar, os sujeitos contribuíram com as modalidades: higiene e febre. A partir dessas evocações, os profissionais evidenciaram Que os elementos que contribuem para infecção hospitalar estão relacionados com a higiene de uma forma geral e com o aparecimento de sinal como a febre.

Ainda com relação ao mesmo fator, apresentaram como sentido de procedimentos invasivos: punção e cuidado. As evocações representam palavras Que reforçam a necessidade de reflexão sobre a proteção individual dos profissionais de Enfermagem com relação a eles próprios, sendo importante seguir as medidas de precaução padrão designadas para o atendimento de todos os clientes, independente do diagnóstico ou da condição infecciosa presumida.

Pesquisa sobre a infecção hospitalar realizada no Piauí, aborda o modo-de-ser-cuidado da Enfermagem das áreas críticas do Hospital Getúlio Vargas (HGV), como sentimentos ocultos, não muito visualizados na assistência, mas existentes e capazes, de certa forma, de contribuir para um novo desenho do cuidar de Enfermagem. A identificação desses sentimentos foi feita com certa dificuldade, Quando os profissionais da Enfermagem demonstraram desconforto para falarem dos seus sentimentos, vivências e emoções ${ }^{(17)}$.

Assim, essas dificuldades reveladas pelos profissionais de Enfermagem, acredita-se serem resultante do modelo Que tem predominado no assistir da profissão, o Qual tem como base a resolução de problemas dos clientes, sem muita preocupação com o aparecimento de complicações capazes de causar danos irreparáveis à saúde, podendo levar até à morte, como é o caso das infecções hospitalares. Rotineiramente, a maioria desses profissionais não atenta para a importância da Responsabilidade Civil, pelo desconhecimento das implicações civil, penal e ética, decorrentes da falta de uma prática no exercício adequado.

Contudo, os profissionais de Enfermagem também são os responsáveis por prevenir e controlar sistematicamente os processos de contaminação Que possam causar danos à clientela durante assistência de sua profissão. Essa preocupação está demonstrada no decorrer dos últimos anos, Quando várias Resoluções têm sido publicadas dispondo sobre os mais variados aspectos Que regulamentam o exercício da profissão ${ }^{(18)}$.

\section{CONSIDERAÇÕES FINAIS}

Os profissionais da Enfermagem sempre estiveram presentes no processo do cuidar, Que, ao longo dos tempos, deixou de ser exercido por práticos para ser desenvolvido por pessoas com Qualificação específica, e as apreensões das Representações Sociais dos procedimentos invasivos, construídas por profissionais de Enfermagem de nível médio e superior, revelam que o processo de formação e de educação permanente é decisivo e até mesmo determinante para a adesão destes profissionais às práticas de procedimentos invasivos e controle das infecções hospitalares.

O campo representacional dos sujeitos do estudo indicou uma visão ampla do problema das infecções hospitalares e suas consequências, objetivadas através das evocações: doença, contaminação, morte, aumento de permanência, higiene e febre.

Por outro lado, o estímulo procedimentos invasivos, objetivado como risco, sonda, punção, cuidado, intubação, assepsia e acesso, mostra Que a ênfase dada pelos profissionais ao reconhecimento do valor da proteção e prevenção responde aos apelos do seu grupo social e corroboram com a proposta de um programa de controle de infecção hospitalar Que atenda às precauções padrões.

Observa-se que na Análise Fatorial de Correspondência do estudo, algumas palavras tiveram contribuição significativa nos dois fatores F1 e F2. Como resposta ao estímulo infecção hospitalar, a palavra doença foi a modalidade evocada Que mais contribuiu para os dois fatores.

Como resposta ao estímulo procedimentos invasivos, as palavras punção e cuidado foram as modalidades evocadas Que contribuíram com os dois fatores.

Assim, a combinação dos dois critérios de maior frequência de evocações e contribuição nos dois fatores, resultaram nas palavras doença, punção e cuidado, como evocações mais significativas pertencentes à representação dos sujeitos da pesQuisa sobre os procedimentos invasivos.

Dessa forma, foi possível apreender os aspectos psicossociais presentes nas evocações dos sujeitos, como componentes sociais determinantes das práticas de procedimentos invasivos Que contribuem para orientação de condutas e construção de conhecimentos acerca desses procedimentos relacionados com o controle da infecção.

As Representações Sociais dos sujeitos pesquisados levam à constatação de Que os riscos próprios da profissão são palpáveis e praticamente inerentes à ação profissional no contexto hospitalar, sendo Que os profissionais reconhecem esta situação e condição. Porém, não foram percebidos preocupação e conhecimento acerca da condição de vir a responder penal e civilmente por seus atos na perspectiva da responsabilidade civil, passando ao largo, no campo representacional, esta preocupação, sem desconsiderar em nenhuma circunstância desta análise as condições precárias de trabalho a Que estes profissionais estão submetidos Que podem inclusive determinar a adoção de atitudes não favoráveis ao controle das IH. 


\section{REFERÊNCIAS}

1. Ministério da Saúde (BR). Portaria No 2.6I6, de 12 de maio de 1998. Expede na forma de anexos diretrizes e normas para a prevenção e controle das infecções hospitalares. Diário Oficial União 1998.

2. Pereira MS, Moriya TM. Controle de infecção hospitalar. Rev Bras de Enferm 1988; 41 (1): 39-45.

3. Zanon VNI. Infecção hospitalar. Rio de Janeiro: Médica Científica; 1987.

4. Yamaushi NI, Munhoz CHF, Ferreira AMTGB. Procedimentos Invasivos. In: Fernandes AT, organizador. Infecção hospitalar e suas interfaces na área da saúde. São Paulo: Atheneu; 2000. p. 957-97.

5. Diniz MH. Curso de Direito Civil Brasileiro. São Paulo: Saraiva; 2003.

6. Senado Feeral (BR). Novo Código Civil: Exposição de motivos e textos selecionados.Brasília: Senado Federal, Subsecretaria de Edições Técnicas; 2002.

7. Conselho Federal de Enfermagem (BR). Código de ética dos profissionais de enfermagem. [citado 20 nov 2007]. Disponível em: http://www.coren-df.org.br/site/print.asp?ArticlesID=777

8. Tavares CMM, Teixeira ER. Pesquisa em enfermagem: novas metodologias aplicadas. Rio de Janeiro: Guanabara-Koogan; 1998.

9. Moscovici S. Representações sociais: investigação em psicologia social. Petrópolis: Vozes; 2003.

10. Jodelet D. Represéntations sociales: un domaine en expansion. In: Jodelet D. Les représentations sociales. Paris: Presses Universitaires de France; 1989.

11. Coutinho MPL. Representações sociais: abordagem interdisciplinar. João Pessoa: Universitária UFPB; 2003.

12. Tipple AFV, Pereira MS, Hayashida M, Moriya TM, Souza ACS O ensino do controle de infecção: um ensaio teórico prático. Rev Latino-Am Enfermagem 2003; I I (2): 245 - 250.

13. Dias Neto IA, Silva LDM, Martins ACP. Prevalência e susceptibilidade bacteriana da infecção urinária hospitalar. Rev Acta Cirúrg Bras 2003; 18(5): 36-38.

14. Sznelwar LI, Lancman S, WU MI. Análise do trabalho e serviço de limpeza hospitalar: contribuição da ergonomia e da psicodinâmica do trabalho. Prod 2004; I 4(3): 45-57.

15. Teixeira P, Valle S. Biossegurança:uma abordagem multidisciplinar. Rio de Janeiro: Fio Cruz; 1996. 